\title{
Outbreak of infantile enteritis caused by enterotoxigenic Escherichia coli O6.H16
}

\author{
B. ROWE, R. J. GROSS, S. M. SCOTLAND, A. E. WRIGHT, G. N. SHILlOM, \\ AND N. J. HUNTER \\ From the Salmonella and Shigella Reference Laboratory, Central Public Health Laboratory, Colindale \\ Avenue, London NW9 5HT, and the Gloucester Royal Hospital, Gloucester, UK
}

SUMMARY Ten out of 18 babies at risk developed enteritis in an outbreak in a special-care baby unit. Salmonella, Shigella, and Escherichia coli belonging to the traditional infantile enteropathogenic serogroups were not found in faeces from the babies and the staff, and no virus particles were found by electron microscopy. Detailed serotyping of $E$. coli showed that five of the 10 babies with diarrhoea and one of the eight without diarrhoea were excreting $E$. coli O6.H16. All six isolates of this serotype produced both heat-labile and heat-stable enterotoxin. Enterotoxigenic strains of $E$. coli O6.H16 have caused outbreaks of enteritis in adults in the USA and Japan.

Escherichia coli strains belonging to the traditional infantile enteropathogenic serotypes (EPEC) are a well-documented cause of epidemic infantile enteritis in the British Isles. However, such epidemic strains are usually non-enterotoxigenic according to currently available test systems (Gross et al., 1976) and may cause diarrhoea by an as yet undescribed mechanism (Rowe et al., 1977). Enterotoxigenic $E$. coli (ETEC) are an important cause of enteritis in adults, particularly in areas of poor hygiene and especially in travellers recently arrived in such areas. Their importance as a cause of infantile enteritis is less well documented.

Gross et al. (1976) suggested that if EPEC are not found when investigating an outbreak of infantile enteritis $E$. coli strains should be serotyped in detail, using the complete range of antisera, and be tested for enterotoxin production. Application of these recommendations in investigating an outbreak of enteritis in a special-care baby unit in the British Isles led to the detection of an epidemic enterotoxigenic E. coli strain.

\section{Patients and methods}

The special-care baby unit, a spacious modern unit with a capacity for 20 cots, was divided into a six-cot area used for semi-intensive care, two four-cot rooms, and four single cubicles. Two rooms were used for

Received for publication 12 September 1977 isolation, although not ideal for the purpose. Babies were received from the central delivery suite in the Maternity Hospital, of which the baby unit was an integral part. Babies were also admitted from a nearby general-practitioner unit and other outlying units. There were about 400 admissions each year.

When the outbreak started 18 babies were at risk. The first case of diarrhoea was a 4-day-old premature infant (1.96 kg at 34 weeks' gestation). The patient was immediately transferred from the semi-intensive area, where the infant was being nursed with four others, to an isolation cubicle. After intravenous fluids the baby recovered within 48 hours but transfer back to the ward was delayed for seven days until microbiological investigations were negative. On that day three further cases of diarrhoea occurred in babies in cubicles, and three further cases the following day. The infant who was the first case was returned to an isolation cubicle, and further admissions to the unit were suspended. A total of 10 babies developed diarrhoea. Four required intravenous infusions. There were no fatalities.

MICROBIOLOGICAL EXAMINATION

Faecal specimens from the babies and staff in the unit were examined by routine techniques for Salmonella and Shigella. The traditional infantile enteropathogenic serotypes of $E$. coli (EPEC) were sought using antisera for O groups O18ac, O26, O44, O55, O86, O111, O112ac, O114, O119, O124, O125, O126, O127, O128, O142. 
In addition faecal specimens from 10 babies with diarrhoea and eight without diarrhoea were subcultured on to McConkey agar and five coliform colonies were selected from each for further examination. The selected colonies were identified biochemically by the methods of Cowan and Steel (1965) and the $E$. coli were serotyped using antisera for $O$ groups $\mathrm{O} 1$ to $\mathrm{O} 164$ and for flagella antigens $\mathrm{H} 1$ to H56 (Ørskov and Ørskov, 1975).

Faecal specimens from 25 members of the staff were examined retrospectively. They were subcultured on to McConkey agar and 10 colonies from each were examined by slide agglutination with an antiserum prepared using $E$. coli O6.K13 (strain number $\mathrm{Su} 4344$ ) as a vaccine. Any colonies giving positive slide agglutination were identified biochemically and serologically.

\section{ENTEROTOXIN TESTING}

One isolate of each serotype found in each specimen was selected for enterotoxin testing. The selected isolates were tested for the production of heat-stable enterotoxin (ST) by the infant mouse test (Dean et al., 1972) and for heat-labile enterotoxin (LT) by the Y1 adrenal cell test (Donta et al., 1974) and the CHO cell test (Guerrant et al., 1974).

\section{VIROLOGICAL EXAMINATION}

Faecal emulsions were inoculated into secondary monkey kidney, human embryo fibroblasts, human embryo kidney, and Hep. 2 for virus isolation. Specimens were examined by electron microscopy.

\section{Results}

Investigations in the clinical laboratory failed to find Salmonella, Shigella, or EPEC in the faecal specimens of any of the babies or staff and the virological tests failed to reveal any significant aetiological agent.

Detailed serotyping of $E$. coli in the reference laboratory showed that five of the 10 babies with diarrhoea and one of the eight babies without diarrhoea were excreting $E$. coli O6.H16, while two babies with diarrhoea and three of those without diarrhoea were excreting $E$. coli O18ac.H-. No other serotype was found in more than one patient. One child who excreted $E$. coli $06 . \mathrm{H} 16$ during a diarrhoeal episode at the beginning of the outbreak excreted $E$. coli O18ac.H- later. During excretion of the latter organism the child was well. Only one member of staff was excreting $E$. coli $\mathrm{O} 6$ but this isolate possessed the flagella antigen $\mathrm{H}$.

The five strains of E. coli O18ac.H-had not been detected in the clinical laboratory even though O18ac antiserum was in routine use. The reference labora- tory confirmed that these strains failed to agglutinate with this antiserum using slide agglutination techniques. Difficulties in identifying this $\mathbf{O}$ group are often encountered, perhaps because strains of it may possess one of several different $\mathrm{K}$ antigens.

All six isolates of $E$. coli O6.H16 produced both ST and LT but enterotoxin production was not detected in strains of E. coli O6.H1 and O18ac.H- or $\bigcirc$ any other serotype.

\section{Discussion}

During the last few years enterotoxigenic $E$. coli (ETEC) have been shown to cause diarrhoea in adults? and to be a significant cause of diarrhoea among $\stackrel{\omega}{\vec{\omega}}$ visitors to areas of poor hygiene (Sack, 1975). However, few studies of epidemic infantile enteritis have $\vec{v}$ included a search for ETEC. Gross et al. (1976) 0 reported that strains of $E$. coli belonging to the traditional infantile enteropathogenic $E$. coli sero- 3 types (EPEC) isolated during outbreaks of infantile enteritis in the British Isles did not produce entero- $\stackrel{\rho}{工}$ toxin detectable in the currently available laboratory $\vec{\bullet}$ tests. Strains of $E$. coli from outbreaks of infantile enteritis should therefore be serotyped and tested for enterotoxin production when routine studies fail to find strains belonging to EPEC serotypes (Rowe et al., 1977). Using such techniques an outbreak of infantile enteritis in a Scottish hospital has been attributed to $E$. coli $\mathrm{O} 159 . \mathrm{H} 20$ producing ST only (Gross et al., 1976), and an outbreak has been described in the USA which was caused by $E$. coli O78.H12, also producing ST only (Ryder et al., 1976). Our study together with these earlier reports shows that ETEC may cause outbreaks of infantile enteritis even in areas of good hygiene in temperate countries. $\frac{0}{3}$

The discovery that the production of enterotoxins by some $E$. coli strains is controlled by a transmissible $\delta$ plasmid suggests the possibility that strains of any $₹$ serotype might acquire such a plasmid. However, $\frac{9}{5}$ there is recent evidence that the distribution of $D$ ETEC among the various $O$ groups of $E$. coli is not random and that they may belong to a restricted $N$ range of $O$ groups, although this range is different ${ }^{\circ}$ from that in which the EPEC are found (Ørskov et 0 $a l ., 1976$ ). Our study supports this concept, since $E$. $N$ coli O6.H16 is not one of the EPEC serotypes. Yet? enterotoxigenic strains belonging to this serotypeco have caused outbreaks of diarrhoeal disease in the $\overparen{\mathbb{D}}$ USA (Morbidity and Mortality, 1975) and Japan $\stackrel{\circ}{+}$ (Kudoh et al., 1977).

Serotyping is a relatively simple technique widely used in clinical laboratories. The available tests for $\AA$ enterotoxin production are unsuitable for routine $\stackrel{\mathbb{D}}{\circ}$ use. The apparent restriction of enterotoxigenic $E$. $\sigma$ coli to certain $\mathrm{O}$ groups offers the possibility of sero- 
typing being used for provisionally identifying potentially enterotoxigenic strains. Enterotoxin production could be confirmed later at a central laboratory. The use of antisera for the $E$. coli $\mathbf{O}$ groups to which ETEC most often belong may prove valuable in investigating outbreaks of infantile enteritis by clinical laboratories.

We thank the Regional Public Health Laboratory, Bristol, for the electron microscopy.

\section{References}

Cowan, S. T., and Steel, K. J. (1965). Manual for the Identification of Medical Bacteria. Cambridge University Press, Cambridge.

Dean, A. G., Ching, Y.-C., Williams, R. G., and Harden, L. B. (1972). Test for Escherichia coli enterotoxin using infant mice: application in a study of diarrhea in children in Honolulu. Journal of Infectious Diseases, 125, 407-411.

Donta, S. T., Moon, H. W., and Whipp, S. C. (1974). Detection of heat-labile Escherichia coli enterotoxin with the use of adrenal cells in tissue culture. Science, 183, 334-335.

Gross, R. J., Rowe, B., Henderson, A., Byatt, M. E., and Maclaurin, J. C. (1976). A new Escherichia coli Ogroup, 0159 , associated with outbreaks of enteritis in infants. Scandinavian Journal of Infectious Diseases, 8, 195-198.

Gross, R. J., Rowe, B., and Scotland, S. M. (1976). Enterotoxin testing of Escherichia coli causing epidemic infantile enteritis in the U.K. Lancet, 1, 629-631.

Guerrant, R. L., Brunton, L. L., Schnaitman, T. C., Rebhun, L. I., and Gilman, A. G. (1974). Cyclic adenosine monophosphate and alteration of chinese hamster ovary cell morphology: a rapid, sensitive in vitro assay for the enterotoxins of Vibrio cholerae and Escherichia coli. Infection and Immunity, 10, 320-327.

Kudoh, Y., Zen-Yoji, H., Matsushita, S., Sakai, S., and Maruyama, T. (1977). Outbreaks of acute enteritis due to heat-stable enterotoxin-producing strains of Escherichia coli. Microbiology and Immunology, 21, 175-178.

Morbidity and Mortality. Follow-up on outbreak of gastrointestinal illness at Crater Lake National Park, Oregon. (1975). 24, 261-262.

Ørskov, F., and Ørskov, I. (1975). Escherichia coli O:H serotypes isolated from human blood. Acta Pathologica et Microbiologica Scandinavica Sect.B. 83, 595-600.

Ørskov, F., Ørskov, I., Evans, D. J., Jr., Sack, R. B., Sack, D. A., and Wadström, T. (1976). Special Escherichia coli serotypes among enterotoxigenic strains from diarrhoea in adults and children. Medical Microbiology and Immunology, 162, 73-80.

Rowe, B., Scotland, S. M., and Gross, R. J. (1977). Enterotoxigenic Escherichia coli causing infantile enteritis in Britain (Letter). Lancet, 1, 90-91.

Ryder, R. W., Wachsmuth, I. K., Buxton, A. E., Evans, D. G., DuPont, H. L., Mason, E., and Barrett, F F. (1976). Infantile diarrhea produced by heat-stable enterotoxigenic Escherichia coli. New England Journal of Medicine, 295, 849-853.

Sack, R. B. (1975). Human diarrhoeal disease caused by enterotoxigenic Escherichia coli. Annual Review of Microbiology, 29, 333-353. 